\title{
Semantic Bleaching and the Emergence of New Pronouns in AAVE
}

\author{
Taylor Jones \& Christopher Hall* \\ LSA Annual Meeting, Portland, January 8 - 11, 2015
}

1. Introduction. Some vernacular registers of African American English (AAVE) now make available to speakers a new set of lexical items, including pronouns, which are the result of the grammatical reanalysis of phrases using the AAVE reflex of the English slur nigger:

(1) a nigga haven't made myself breakfast yet

I haven't made myself breakfast yet

Here, we discuss emerging lexical items from that set in AAVE - first person pronouns a nigga and niggas(phonologically,/ənigə/, /nigəz/), second person VOCATIVES nigga (/nigə/) and ma nigga (/mənigə/), and third person HONORIFICS this/that/my nigga. We demonstrate that the first person forms are in fact pronouns, and not IMPOSTERS (Collins \& Postal, 2012). We begin by demonstrating phonological differentiation in AAVE between nigga and the slur nigger. We then demonstrate the semantic bleaching of nigga, which now has a meaning roughly equivalent to General American (GA) guy, as distinct from the still extant (and sometimes homophonous) slur nigger. Then we discuss the difference between imposter DPs and bona fide pronouns, before showing that, for all relevant tests, the new n-forms pattern with pronouns. Subsequently, we discuss a politeness distinction between vocatives, and social distance honorifics. We conclude by discussing relevant animacy phenomena.

2. Different Words. Because the slur nigger is a taboo word, and because AAVE tends to be r-less and l-less postvocalically (Baugh 1983; Edwards 1997; Foley 1972; Labov et al. 1968; Myhill 1988; Pederson et al. 1986-1992; Williamson 1968; Wolfram and Thomas 2002; Wolfram 1969), there is often disagreement as to the lexical status of nigga. We argue that the 'folk theory' is correct: the two are different words. This is not only borne out by the syntactic evidence presented below, but is supported by phonological evidence as well. While matters are complicated by the fact that intervocalic 'linking-r' does not always appear in AAVE, speakers using the slur will intentionally emphasize the coda /r/. Moreover, compounds clearly distinguish between the two words, so there is a distinction between real niggaism (['nıgə,Izm], 'keeping things down to earth') and

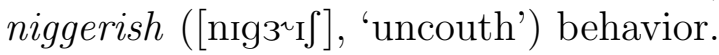

3. Semantic Bleaching. The fact that nigga functions as a different lexical item is the result of SEMANTIC BLEACHING, the process whereby a morpheme or word is 'bleached' of (viz. 'loses') its orignal meaning over time (cf. Haiman 1991). Nigga is no longer marked for race or ethnicity $(2)^{*}$, and is used neutrally and unironically when discussing other offensive terms (3):

*The authors would like to thank William Labov, Gillian Sankoff, John Rickford, Lisa Green, Julie Legate, Don Ringe, Robin Clark, Sonja Lanehart, Anthony Henderson, Steven and Stanley Howse, Bryon McCain II, and Russell Jones. Authors: Taylor Jones, University of Pennsylvania (tayjones@sas.upenn.edu) \& Christopher Hall, CulturePoint (cshall@culturept.com).

*Examples from fieldwork in Harlem, the South Bronx, and West Philddelphia, as well as adapted from 10,000 Tweets collected by the authors, posts on Facebook, and popular entertainment. 
(2) There's this White/Asian/Black/African nigga in my class, who...

(3) I think it's sooo disrespectful when a nigga call a girl a bitch.

The default for nigga is [+human] and [+male], although we will argue that the picture is slightly more complicated (v.i., section 7).

4. Pronouns. For some speakers, semantically bleached nigga has given rise to new words, some of which have clear pronominal - and crucially not imposter - behavior. Collins and Postal define as an imposter any "notionally $1^{\text {st }}$ or $2^{\text {nd }}$ person DP that is grammatically $3^{\text {rd }}$ person," and explicitly state that "even though they denote the speaker or addressee, "all English imposters determine third person verbal agreement" $(4,5)$.

(4) $\operatorname{Daddy}_{i}$ is enjoying himself . $_{\text {. }}$

(5) Would the Baroness like more wine?

In all testable respects, first person a nigga patterns with pronouns and not with imposters. While we use the de facto standard orthography here, a nigga is phonologically reduced to [ənigə], and does not allow intervening words (6), moreover, a change in pronunciation to [er.nıgə] eliminates the possibility of a first person reading. A nigga patterns with pronouns with respect to binding conditions: it binds pronouns in the relevant domain (7), cannot be bound by a local or c-commanding pronominal antecedent (8), binds anaphor in the relevant domain (9), and for some speakers, triggers first person verbal agreement (10). It also lacks the $\theta$-role restrictions that the equivalent imposter $a$ brotha has (11).

(6) ${ }^{*}$ A handsome/charming/affable nigga ${ }_{i}$ treated myself f $_{i}$ to a new suit.

(7) You stuck by a nigga ${ }_{i}$ like $\mathbf{m y}_{i}$ left hand.

(8) $* \mathbf{I}_{i}$ washed a nigga $\mathbf{a}_{i}$.

(9) Ever since a nigga $\mathbf{a}_{i}$ taught myself $_{i}$ how to roll, I've smoked everyday.

(10) A nigga ${ }_{i}$ haven't had donuts in months, $\mathbf{I}_{i}$ ain't livin' right.

(11) A nigga/*a brotha arrived. (n.b. $1^{\text {st }}$ person reading of a brotha impossible with unaccusatives.)

First person plural niggas patterns similarly, however the binding and agreement facts are not conclusively provable, given insufficient evidence from AAVE (and more broadly, English) morphosyntax, although, it is conceptually economical and appealing to treat first person plural niggas as $\emptyset$-nıgə-z, analagous to singular ə-nigə- $\emptyset$. 
5. Vocatives. Speakers of the register of AAVE under discussion here also have the vocatives nigga and my nigga which are fixed lexical items that mark social distance. The latter is phonologically reduced to [mənigə] (cf. my nigga [name], below), and does not allow anything to intervene between the prefix and nigga, although spelling does not often reflect these facts. The distinction between the bare form nigga and the prefixed my nigga is essentially a pragmatic distinction, where nigga places the speaker higher on a social hierarchy than her interlocutor, whereas my nigga places speaker and listener on equal social footing, or places the speaker below her interlocutor. As such, it is equivalent to a $\mathrm{T} / \mathrm{V}$ distinction, as in the Romance languages. The choice of vocative affects meaning, as in:

(12) My nigga, what do you think?

(13) Nigga, what do you think?

The first is a neutral or polite invitation to comment, the second is a cutting rhetorical question implying the interlocutor has just asked a stupid question.

6. Honorifics. Similarly, there are three honorific markers of social distance available to speakers of this register of AAVE. When introducing a new person to the discourse, a speaker can optionally encode friendship status through use of my nigga [name] and that nigga [name], where the former encodes close friendship (14) and the latter encodes that the speaker and person under discussion are not close friends, no matter how famous the subject is $(15,16)$. Similarly this nigga [name] signals derision or indignation (cf. Green, 2002, regarding indignant come ) (17).

(14) Y'all pray for my nigga teezy please.

(15) That nigga Ellen Degeneres been getting away with those coke head dance

moves for too long now.

(16) Give that nigga Obama four more years.

(17) This nigga Suge out here faking heart attacks to get out of custody.

7. Animacy Effects. There is a significant relationship between the $n$-forms discussed here and the phenomonon of (semantico-syntactic) animacy. Recent research suggests AAVE is sensitive to animacy in other domains (McLaughlin, 2014). Animacy can be treated on a number of scales (Comrie, 1981), two of which are relevant here. First, a hierarchy in which:

Free adult males $>$ other humans $>$ pets and domesticated animals $>$ other sentient creatures $>$ forces of nature $>$ moving things $>$ non-moving inert things

Semantically bleached third person nigga, while default human and male, extends down the animacy hierarchy to include women, children, domesticated animals, and sentient creatures, but not acts of nature or wholly inert objects (e.g., stones): 


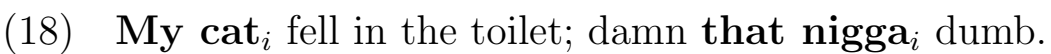

(19) $\mathbf{A}$ wasp $_{i}$ just stung me on some drive-by type shit, nigga $\mathbf{a}_{i}$ just stung me and bounced.

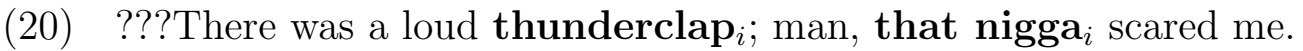

The other relevant scale is the Silverstein hierarchy (1976):

$1^{\text {st }}$ person pronouns $>2^{\text {nd }}$ person pronouns $>3^{\text {rd }}$ person proximate $>3^{\text {rd }}$ person obviate $>$ proper names $>$ kin terms $>$ human nouns $>$ animate nouns $>$ inanimate nouns

We contend that given such a hierarchies, the absence of a complete pronominal $n$ form paradigm is not problematic, and the data are suggestive of an interaction between syntactically bleached but high animacy nigga and universally high-animacy syntactic types (perhaps triggering the change from imposter to pronoun). Here we believe it sufficient to note that animacy is relevant, and leave a more thorough treatment for future work.

8. Conclusion. As we have demonstrated, some speakers of one register of AAVE have innovative syntactic forms built from the semantically bleached reflex of a racial slur, including a robust set of grammatical forms. We do not have the space to pursue discussion of the origin and trajectory of these terms, but we can say in passing that such terms were unattested before the 1970s, and so commonplace as to be widely understood in popular entertainment by the early 1990s. They are not yet universally used, and so we are uniquely positioned to observe a grammatical change as it happens.

\section{Selected References.}

BAUGH, JOHN. 1983. Black street speech. Austin, TX: University of Texas Press. COLLINS, CHRIS, AND PAUL MARTIN POSTAL. 2012. Imposters: a study of pronominal agreement. MIT Press.

EDWARDS, WALTER F. 1997. The variable persistence of Southern vernacular sounds in the speech of inner-city Black Detroiters. Language variety in the South revisited, ed. by Cynthia Bernstein, Thomas Nunnally and Robin Sabino, 76-86. Tuscaloosa, AL: University of Alabama Press.

FOLEY, LAWRENCE M. 1972. A phonological and lexical study of the speech of Tuscaloosa County, Alabama (Publication of the American Dialect Society 58). Tuscaloosa, AL: University of Alabama Press.

LABOV, WILLIAM, PAUL COHEN, CLARENCE ROBINS, AND JOHN LEWIS. 1968. A study of the non-standard English of Negro and Puerto Rican speakers in New York City. Report on cooperative research project 3288. New York, NY: Columbia University.

MYHILL, JOHN. 1988. Postvocalic /r/ as an index of integration into the BEV speech community. American Speech 63.203-13

PEDERSON, LEE A., SUSAN LEAS MCDANIEL, GUY BAILEY, MARVIN H. BASSET, CAROL M. ADAMS, CAISHENG LIAO, AND MICHAEL B. MONTGOMERY. (eds.) 1986-1992. The Linguistic Atlas of the Gulf States, 7 vols. Athens, GA: University of Georgia Press.

THOMAS, ERIK R. 2007. "Phonological and phonetic characteristics of African American vernacular English." Language and Linguistics Compass 1.5. 450-475.

WOLFRAM, WALT, AND ERIK R. THOMAS. 2002. The development of African American English (Language in society, vol. 31). Oxford, UK/Malden, MA: Blackwell. 